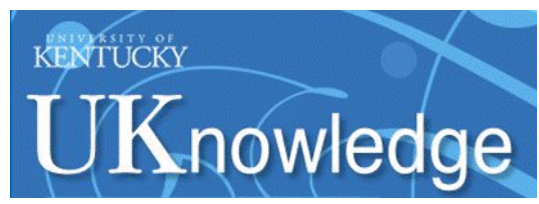

University of Kentucky

UKnowledge

$1-1-2004$

\title{
Developing a Pediatric Oral Health Therapist to Help Address Oral Health Disparities Among Children
}

David A. Nash

University of Kentucky, danash@uky.edu

Follow this and additional works at: https://uknowledge.uky.edu/ohs_facpub

Part of the Dentistry Commons

Right click to open a feedback form in a new tab to let us know how this document benefits you.

\section{Repository Citation}

Nash, David A., "Developing a Pediatric Oral Health Therapist to Help Address Oral Health Disparities Among Children" (2004). Oral Health Science Faculty Publications. 11.

https://uknowledge.uky.edu/ohs_facpub/11

This Article is brought to you for free and open access by the Oral Health Science at UKnowledge. It has been accepted for inclusion in Oral Health Science Faculty Publications by an authorized administrator of UKnowledge. For more information, please contact UKnowledge@lsv.uky.edu. 


\title{
Developing a Pediatric Oral Health Therapist to Help Address Oral Health Disparities Among Children
}

\author{
Notes/Citation Information \\ Published in the Journal of Dental Education, v. 68, no. 1, p. 8-20. \\ Copyright (C) 2004 American Dental Education Association \\ Reprinted by permission of Journal of Dental Education, Volume 68, 1 (January 2004). Copyright 2004 by \\ the American Dental Education Association. http://www.jdentaled.org
}


Reprinted by permission of Journal of Dental Education, Volume 68, 1 (January 2004). Copyright 2004 by the American Dental Education Association. http://www.jdentaled.org 


\title{
Developing a Pediatric Oral Health Therapist to Help Address Oral Health Disparities Among Children
}

\author{
David A. Nash, D.M.D., M.S., Ed.D. \\ Abstract: Oral Health in America: A Report of the Surgeon General documented the profound and significant disparities that \\ exist in the oral health of children in the United States. Recently, the country has been issued a National Call to Action to \\ Promote Oral Health, under the leadership of the Office of the Surgeon General. Among the significant factors contributing to the \\ disparities problem is the access to oral health care by disadvantaged populations. There are inadequate numbers of dentists able \\ and willing to treat children, particularly poor and minority children. In the early part of the twentieth century, New Zealand \\ faced a significant problem with oral disease among its children and introduced a School Dental Service staffed by allied dental \\ professionals, known as "school dental nurses," who had received two years training in caring for the teeth of children. A number \\ of other countries have since adopted this model. This article reviews attempts to develop a comparable approach in the United \\ States. Furthermore, it justifies and advocates the development of pediatric oral health therapists in the United States as a means \\ of addressing the disparities problem that exists in this nation. These pediatric oral health therapists would be trained in a two- \\ year program to provide dental care services to children. The article concludes by asserting that such action is a practical and \\ cost-effective way for dentistry to fulfill its professional obligation to care for the oral health of all children, thus ensuring justice \\ in oral health for America's children.
}

Dr. Nash is the William R. Willard Professor of Dental Education and Professor of Pediatric Dentistry, College of Dentistry, University of Kentucky. Direct correspondence and requests for reprints to him at the College of Dentistry, University of Kentucky, Lexington, KY 40536-0297; 859-323-2026 phone; 859-323-4685 fax; danash@email.uky.edu.

Key words: access, disparities, children's oral health, allied dental professionals, dental therapy, pediatric oral health therapist

Submitted for publication 8/6/03; accepted 10/28/03

I n 2002 the Robert Wood Johnson Foundation (RWJ) commissioned the National Conference of State Legislatures to conduct a study of policy barriers to accessing oral health care and to suggest opportunities for intervention by the foundation. ${ }^{1}$ The report expressed the view that "those who work on oral health issues seem very much rooted in (and mired in) the present, and are not thinking about bold new solutions." Among the several recommendations to RWJ was one to fund "out-of-the-box" thinking.

Developing a pediatric oral health therapist is not a bold new solution, nor is it out-of-the-box thinking. While it may be out-of-the-box in the United States, it is clearly within-the-box of international thinking. This potential solution for helping address the access problem for low-income and minority children in the United States is actually an old solution that was boldly undertaken by the New Zealand Dental Association and the people of that nation, who in 1921 developed the now internationally famous New
Zealand school dental nurse, ${ }^{2-4}$ the progenitor of the pediatric oral health therapist advocated in this article.

The disparities that exist in oral health among children in the United States have been documented in Oral Health in America: A Report of the Surgeon General $^{5}$ and the recent National Call to Action to Promote Oral Health. ${ }^{6}$ This article will review these disparities in the context of exploring one strategy to help address the problem, and it will suggest reasons for these disparities, focusing primarily on the problems of access to dental care for which the dental profession has not provided a solution. It will also review the use of allied dental professionals in other countries, with the New Zealand school dental nurse (now called a dental therapist) as an example; describe the curriculum in which these allied professionals are trained; delineate the competencies they attain; profile the environment in which they practice; and suggest means by which these international 
programs can inform the development of pediatric oral health therapists to help address dental care disparities in the United States. Finally, the existence of oral health disparities in the world's most affluent nation will be addressed as a moral problem, an issue of justice, and a problem American dentistry must resolve if it is to validate its continuation as a profession, in the classic sense of that word and concept. President John Kennedy once said that "Children may be the victims of fate- they must never be the victims of neglect."

\section{Epidemiology of Oral Disease and Access to Care}

A recent article in the journal Pediatrics identified dental care as the most prevalent unmet health need in U.S. children. ${ }^{7}$ Numerous studies, many of which were cited in the Surgeon General's Report, document the profound and significant disparities in oral health among America's children. Children lose 52 million hours of school time each year due to dental problems, ${ }^{8}$ and poor children experience nearly twelve times as many restricted activity days from dental disease as do children from higher income families. ${ }^{9}$ Eighty percent of dental disease among children is found in 20-25 percent of children (approximately 18 million), and these are primarily children from African-American, Hispanic, American Indian/Alaskan Native, and low-income families. ${ }^{10}$ The prevalence and severity of dental disease are linked to socioeconomic status across all age groups.

Access can be understood as the ability to personally utilize professional health services to achieve optimal health results. Clearly, the problem of access to oral health care for children is multidimensional; involving complex social, cultural, educational, and financial issues. Access to oral health care also is influenced by the system that the profession of dentistry operates today to deliver its services to the public.

Relevant facts regarding children's access to oral health care include the following:

- Children with no dental insurance are three times more likely to have an unmet dental need than their counterparts with either public or private insurance. $^{5}$

- Children from families with incomes below 200 percent of the federal poverty level (FPL) are three times more likely to have unmet dental care needs than children from families at or above 200 percent of the FPL. ${ }^{7}$ One in four children are born into families with incomes below the FPL,${ }^{6}$ which in 2003 was $\$ 18,400$ for a family of four. ${ }^{11}$

- Nearly 25 percent of America's children are entitled to comprehensive dental coverage by Medicaid, yet fewer than one in five of these received a single preventive visit in a recent year-long study period. ${ }^{12}$ Poor children have one-half the number of dental visits of higher income children. ${ }^{9}$

- One in four American children have not seen a dentist prior to beginning kindergarten. ${ }^{6}$

- While almost 90 percent of poor children have a usual source of medical care and 74 percent of poor children nineteen to thirty-five months of age receive all their vaccinations, only 22 percent of all children under age six years receive any dental care. $^{13}$

\section{Barriers to Access}

While multiple barriers to access have been identified, ${ }^{1,5,14,15}$ two will be examined here in the context of advocating for the development of a pediatric oral health therapist. These two are dentists and leadership/advocacy.

\section{Dentists}

Dentists are among the more significant barriers to access for disadvantaged populations: their numbers, distribution, and ethnicity; their education; and their attitudes.

First, the number and distribution of dentists in the United States contribute to the inadequate access to care for children in greatest need. The dentist/population is declining from its peak of 59.5/ 100,000 in 1990 and will drop from the current 58/ 100,000 to $52.7 / 100,000$ in the year 2020 - a decline of 10 percent. ${ }^{16,17}$ Compounding the access issue is the location of dental practices. The overwhelming majority of dentists practice in suburbia, with few practicing in the rural and inner-city areas where children with the greatest need live. In fact, the number of federally designated shortage areas has more than doubled from 792 in 1993 to 1,895 in 2002. ${ }^{14}$

Approximately 12 percent of the population is African-American, but only 2.2 percent of dentists are. Individuals of Hispanic ethnicity make up another 10.7 percent of the population, yet only 2.8 percent of dentists are Hispanic. ${ }^{18}$ Less than 5 per- 
cent of entering student dentists are African-American, and less than 5 percent are Hispanic. ${ }^{19}$ Yet the demographics of oral disease indicate that these two minority groups comprise a significant proportion of the disparity problem.

A second barrier is that student dentists do not receive adequate instruction and experience in treating children. In a recent study entitled "U.S. Predoctoral Education in Pediatric Dentistry: Its Impact on Access to Dental Care," Seale and Casamassimo concluded that "U.S. pediatric dentistry predoctoral programs have faculty and patient pool limitations that affect competency achievement and adversely affect training and practice." 20

The number of pediatric dentists also contributes to access barriers for children. There has been a significant increase in the number of pediatric dentists over the past thirty years, but there are still only 4,357 trained specialists in children's dentistry practicing in the United States today. ${ }^{21}$ Compare this with the 57,000 pediatricians who care for the general health of the nation's children. ${ }^{22}$

In a President's Report entitled "We Need Help," Dr. Paul Casamassimo, then-president of the American Academy of Pediatric Dentistry, stated it bluntly and well: "even with a Herculean increase in training positions [for pediatric dentists], improved workforce distribution, and better reimbursement and management of public programs, pediatric dentistry [the specialty] will never be able to solve this national problem [of disparities] alone. We need help."23

The third factor that contributes to access barriers is the attitude of dentists. Dentists generally do not want to treat publicly insured children, be they children covered by Medicaid or the State Children's Insurance Program (S-CHIP). It is difficult to discuss the issue of access to care, particularly when focusing on the disparities that exist in oral health among America's children, without referencing the Medicaid system. Medicaid provides an entitlement to comprehensive dental services for children who live at 150 percent of the federal poverty level ( $\$ 27,600$ for a family of four in 2003) or below; such care is a mandate. ${ }^{24}$ The S-CHIP program, ${ }^{25}$ authorized by Congress in 1997, extends dental services to children living at 200 percent of poverty $(\$ 36,800$ for a family of four in 2003) or below. Yet Medicaid and S-CHIP fail to meet the oral health needs of America's children.

Dentists offer multiple reasons for failing to treat children with publicly financed insurance, including low reimbursement schedules, demanding paper work and billing requirements, and the frequent failure of parents of these children to keep scheduled appointments. A 1996 study indicated only 10 percent of America's dentists participate in the nation's program to help ensure access to oral health care for poor American children. ${ }^{12}$ The report to RWJ by the National Conference of State Legislatures (NCSL) states that even though reimbursement rates may be dismal, many state legislators believe that dentists "have a community service obligation ... [to participate in these programs], that they are not meeting."

However, reimbursement does not appear to be the major issue. The General Accounting Office released a report in 2000 stating that "raising reimbursement rates - a step 40 states have taken recently - appears to result in a marginal increase in use, but not consistently." ${ }^{15}$ For example, the state of Maine increased its fees for dental services by 40 percent in 1998, but utilization increased by only 2 percent. The state of Indiana increased its Medicaid reimbursement rates to those approximating private insurance, and dentist participation increased by 6 percent - but total participation by dentists was only 26 percent. If raising reimbursement rates is a component of the solution to the Medicaid/S-CHIP dilemma, such is not likely to happen any time soon, as states are struggling to deal with significantly shrinking state revenues.

The problem is more complex than just reimbursement. Most dentists are already as busy as they care to be, as they manage the increasing number of baby-boomers and others who require implants, esthetic dentistry, and other complex services in high demand. The NCSL study indicated that dentists do not believe they need to see more patients to deal with the access issue, particularly when this action would mean seeing publicly insured patients. There is a significant cultural issue at work. Many dentists just do not want publicly insured patients in the reception areas and offices.

Dentists, in general, are also leery of any program affecting their practices that has any sort of government relationship; it is the private practice of dentistry. American dentistry has relentlessly eschewed government programs it believes might negatively impact private practice even though such programming could improve access to care for disadvantaged populations. In a recent issue of the Journal of the Massachusetts Dental Society, coeditors Drs. Norman and David Becker, in an editorial entitled "Raise Your Voice," commented that "the 
problem of children's untreated dental disease is beyond the scope of an organized charitable function ... the solution must be found in government programs." 26

As a result of the failure of dentistry to fulfill its professional obligation to care for the health of the public, society is becoming increasing impatient with dentists. This is borne out by informative, but disturbing, comments made to the researchers in the NCSL study. One consistent finding was that there is a steady undercurrent of negative feelings about dentists among many of the people interviewed. People in every state included in the study made some potentially offensive and controversial comments about typical personality types of dentist: they are difficult to work with, extremely independent, resistant to change, and don't partner well with other professionals. ${ }^{1}$

If dentistry fails to engage and creatively develop solutions to the problem of oral health care for the poor and disadvantaged (especially children), we run the serious risk of losing the status a society grants to a profession and jeopardizing the monopoly we have received to practice dentistry.

\section{Lack of Effective Leadership/ Advocacy}

The NCSL report to RWJ further states that "a consistent theme . . . is the lack of effective advocacy for oral health issues in general and access to dental care for low-income people in particular."1 Those individuals who form public policy, both at the state and federal level, have a low level of awareness, knowledge, and/or interest concerning issues of oral health. There are few champions of the issue in the halls of Congress or our state capitols. And there are not strong coalitions of support among public advocacy bodies.

The report went on to emphasize that the main and most powerful advocacy group for oral health issues in most states is the state dental association. While calling such associations extremely powerful, possibly second in influence only to state medical associations, the report expressed the view that dental associations are "poor advocates for access to dental services, particularly for Medicaid and S-CHIP beneficiaries, as they are perceived as self-serving in seeking increased reimbursement rates." It also suggested they are perceived as providing "false leadership or 'lip service' to access issues for lowincome people."
There is a dearth of leaders in dentistry advocating elimination of barriers to oral health, improving access, and erasing the disparities that exist. One would expect the American Dental Association (ADA) to provide such leadership and advocacy; however, the comment in the NCSL report about "lip service" is probably accurate. Although the ADA supports the concept in principle, it generally opposes any programs that would significantly alter the status quo. It advocates voluntary charity care by its members, but rejects expansion of organized public health programs that would be more effective. The $A D A N e w s^{27}$ recently praised the generosity of dentists in addressing the disparity problem through their donation of time to the "Give Kids a Smile" promotion during National Children's Dental Health Month and stated, without documentation, that dentists provide $\$ 1.7$ billion of charity care annually. The public relations campaign extended to having a legislator (Rep. Cantor, R-Virginia) introduce a resolution in Congress commending dentists for their efforts in addressing the issue of access for poor children and congratulating the American Dental Association on its efforts. Certainly there is merit in feeling good about oneself and one's profession; however, it is difficult to document substantive advocacy for genuine access from the ADA.

In March 2003 a President's Commission of the American Dental Education Association (ADEA) released a report entitled "Improving the Oral Health Status of All Americans: Roles and Responsibilities of Academic Dental Institutions." ${ }^{14}$ The report provides comprehensive background information and justification for change, and while none of the five major categories of recommendations are inappropriate, no specific strategies are advocated that provide creative leadership for change. Rather, the report seems to encourage more intensive continuance of what is been being done - that is, working at the margins, rather than initiating significant change.

The report does propose, as one of its thirtyfour recommendations, educating dental and allied dental students to assume new roles in the prevention, detection, early recognition, and management of a broad range of complex oral and general diseases and conditions in collaboration with their colleagues from other health professions. Including student dentists in the recommendation certainly dilutes any specific emphasis on developing new types of allied professionals or expanding roles for current ones. 


\section{New Zealand's School Dental Nurses}

In 1921 a group of thirty young women entered a two-year training program at Wellington, New Zealand, to study to become "school dental nurses" and in so doing transformed the oral health of the children of a country, laying the basis for what was to become an international movement. ${ }^{2}$ New Zealand's School Dental Service continues to this day and has developed an enviable record of caring for the oral health of all children in New Zealand. There have been changes in the School Dental Service through the years, as well as in the training program for school nurses. However, the basic training and service strategies of over eighty years ago remain intact, having stood the test of time. The program's mantra through the years has been: "we train first-rate technicians, not second-rate dentists." 28

By the 1970s the School Dental Service had grown to approximately 1,350 school dental nurses deployed in schools throughout New Zealand. ${ }^{29}$ At that time there were training programs in Wellington, Auckland, and Christchurch. Each elementary school in New Zealand had its own dental clinic and, in most instances, its own dental nurse, though in some rural areas one dental nurse served more than one school. School dental nurses were employees of the federal health care system and were certified to perform oral examinations; develop treatment plans; provide preventive services, including prophylaxis; administer local anesthesia; prepare and restore primary and young permanent teeth; and extract primary teeth, all under the general supervision of a Ministry of Health dentist. Today, the health care system has been devolved to district health boards, and the school dental therapists (the name change occurred in 1988 by a vote of the dental nurses) "operate under the direction and supervision of the principal dental officer [of the district board], or other [licensed] dentist acting on behalf of the principal dental officer." 30

The advent of high-speed instrumentation, water fluoridation, and modern transportation created changes in the New Zealand School Dental Service. Caries prevalence declined, dental nurses were able to provide care more efficiently, and they could travel to multiple schools more easily. The need for educating school dental nurses was reduced, not only due to these factors, but also because the attrition rate for dental nurses declined as more and more women chose to continue their careers as dental nurses even after marrying and having children. In 1998 there were 569 school dental therapists in New Zealand. ${ }^{31}$ They care for 497,000 school children in over 2,000 schools. ${ }^{32}$ (The population of New Zealand is 4 million.) Due to the decrease in the number of new therapists required, the training programs at Auckland and Christchurch were phased out in the 1980 s, leaving only the one at Wellington. It too was closed in 1999, and the program moved to the national dental school at the University of Otago, in Dunedin. In 2001 Auckland University of Technology established a program as well. The two training programs each admit approximately twenty students each year into the two-year curriculum. ${ }^{33}$

New Zealand's record of oral health for children is notable. All children from age two and onehalf years of age (six months for children at high risk) through age thirteen are eligible to participate in the School Dental Service and receive free comprehensive preventive and restorative care at their local school clinic by the school dental therapist. Children requiring root canal therapy, management of dental trauma, or extraction of permanent teeth are referred to private practitioners, who serve under contract with the government. Enrollment is not compulsory, yet 97 percent of all school-aged children and 56 percent of preschoolers participate. ${ }^{30}$ The School Dental Service remains a New Zealand "icon." ${ }^{34}$ As one colleague expressed it, "The School Dental Service has become an integral component of the New Zealand culture. To Kiwis it is like motherhood, apple pie, and the flag." 35 And it is highly valued, not only by the public, but by dentists as well. $^{32}$

Children who are medically compromised, handicapped, or present significant management problems are enrolled in a Special Dental Benefits program and are served by private practitioners, frequently specialists. There are nine licensed pediatric dentists in New Zealand, with eight of these working in the public sector and only one in private practice. ${ }^{36}$ These special needs children account for some of the 3 percent of children not enrolled in the School Dental Service. Adolescents from fourteen to seventeen are seen in private dental offices under a General Dental Benefits program whose funding is managed by the government on a capitation basis. Children who do not participate in the School Dental Service are generally seen in private practices, but without government financial support for such 
care. After age seventeen, government support for oral health care is limited to emergency care for pain and/or infection.

Dental caries continues to be a significant problem for New Zealand children. It disproportionately affects the Maori (aboriginal New Zealanders), Pacific Islanders, and individuals from lower socioeconomic groups. ${ }^{30,37}$ Only 56 percent of the population drinks fluoridated water. ${ }^{37}$ While the number of decayed, missing, and filled primary and permanent teeth (deft and DMFT) of the children of New Zealand and the United States is roughly comparable, of particular note are the differences in the components of these epidemiological indices. A 2003 report ${ }^{38}$ notes that 53 percent of five year olds are caries-free, with a mean eft of 1.8. At age twelve to thirteen, 42 percent of children are caries-free with a mean MFT of 1.6. What is surprising and fascinating about these data is that the decayed (d/D) components are not included in these figures. When asked about this anomaly, the University of Otago School of Dentistry's epidemiologist indicated that these data represent the children enrolled in the School Dental Service and are collected at the end of each school year. ${ }^{35}$ During the school year the decayed teeth have either been restored or extracted. Because of this emphasis on treatment, essentially all of the school children in New Zealand are free of carious infection at the end of a school year. How does one explain the success of such a program? In a 1972 article in the Journal of the American Dental Association, Friedman suggested that "perhaps it is the unusual circumstance of the application of common sense." ${ }^{28}$

Sir John Walsh, dean of New Zealand's national dental school at the University of Otago from 1946 to 1971 , in addressing the Centennial Conference on Oral Health at Harvard in 1968, suggested the employment of a "Care Index," with such an index being calculated by developing a ratio of the filled teeth component (the $\mathrm{f} / \mathrm{F}$ ) of the deft or the DMFT to the overall deft or DMFT. ${ }^{39,40}$ In 1968, the Care Index in New Zealand was 72 percent-meaning 72 percent of all teeth of children affected by caries had been restored. In the United States, that figure was 23 percent. Dean Walsh made the claim that the Care Index provides a convenient measure of the effectiveness of a country in treating dental caries. Today the Care Index for New Zealand children approximates 100 percent. ${ }^{39}$ In the United States, the Care Index drops significantly when adjusted for income status. For primary teeth it is 72.3 percent for chil- dren at 300 percent of the FPL, but only 48.7 percent for children at 100 percent of the FPL. ${ }^{41}$ For permanent teeth it is 93.2 percent for children at 300 percent of the FPL and only 72.3 percent for children at the 100 percent of the FPL. ${ }^{41}$ Such disparities help underscore the access to care issue for poor children.

\section{Training Dental Therapists in New Zealand and Elsewhere}

A prerequisite for admission to one of the two dental therapy educational programs in New Zealand is graduation from high school, with the completion of a course in biology. Each of the two years in the curriculum is thirty-two weeks in duration. The total curriculum clock hours are approximately 2,400 . During the first year, topics of study include the basic biomedical sciences (general anatomy, histology, biochemistry, immunology, and oral biology), as well as clinical dental sciences (dental caries, periodontal disease, preventive dentistry, patient management, radiography, local anesthesia, restorative dentistry, dental materials, and dental assisting). In the second year, course content includes pulpal pathology, trauma, extraction of primary teeth, clinical oral pathology, developmental anomalies, health promotion/ disease prevention, New Zealand society, the health care delivery system, and recordkeeping, as well as administrative and legal issues associated with dental therapy practice in New Zealand. Approximately 760 hours of the 2,400-hour curriculum are spent in the clinic treating children. Graduates entering the School Dental Service must serve for one year with another school dental therapist who provides assistance, support, and supervision, much in the manner of a residency program. (The preceding general information was obtained through personal communication with Helen Tane, director of the University of Otago's program in dental therapy.)

During my recent visit to New Zealand, members of the dental profession whom I interviewed, both within and outside the School of Dentistry, were highly complimentary of the skills of the dental therapists, as well as the work of the School Dental Service. As a result of legislative changes in 2002, dental therapists are now also able to practice in private offices in New Zealand under the direct supervision of a dentist. ${ }^{42}$ 
The New Zealand school dental nurse/therapist has served as a prototype for adding such a member to the dental team in many additional countries throughout the world, although the specific approach, including practice environments and restrictions, varies from country to country. A 1978 comprehensive assessment of dental nurses worldwide suggested that a major factor predisposing to the introduction of dental nurses was an access problem related to a shortage of dental manpower. ${ }^{43}$ The World Health Organization documents forty-two countries with some variant of a dental therapist; these include Australia, China (Hong Kong), Singapore, Thailand, Malaysia, Great Britain, and Canada. ${ }^{44}$ The Canadian experience is relevant to this discussion as it apparently is the only country in the Western hemisphere to have a training program for dental therapists.

The National School of Dental Therapy for Canada is a component of the First Nations University of Canada in Prince Albert, Saskatchewan. The school, which began in 1972 at Fort Smith in the Northwest Territories, was modeled after New Zealand's, with modifications appropriate for the anticipated service area. ${ }^{45,46}$ The mission was to train dental nurses in a two-year program to provide care for the remote First Nation (aboriginal Indians) and Inuit (Eskimo) villagers of the Canadian North, where dental care was virtually inaccessible. In 1984 the school was moved to Prince Albert due to an inadequate supply of patients in the Fort Smith area. The school continues to prepare dental therapists, with an emphasis on training aboriginal people to care for aboriginal people, specifically on First Nation reserves and in the North.

In the early 1970s, the province of Saskatchewan implemented a school-based dental plan for all children; and in 1972 a dental nurse training program was opened in Regina, Saskatchewan, at the Wascana Institute of Applied Arts and Sciences, now the Saskatchewan Institute of Applied Science and Technology (SIAST) ${ }^{47}$ In the mid-1980s, the province faced budgetary constraints, as well as pressure from dentists to focus on funding dental hygiene rather than dental therapy. As a consequence, the dental therapy training program at Regina was closed in 1987.

Dental therapists are able to work for Health Canada (Canada's ministry of health) on federal First Nation reserves throughout Canada, with the exception of the provinces of Ontario and Quebec. There are eighty-eight dental therapists employed today by
Health Canada ${ }^{48}$ Similar to New Zealand, recent legislation (2001) enables therapists to also work in private dental offices in the province of Saskatchewan, under the indirect supervision of a dentist. ${ }^{49}$ Currently there are 208 licensed dental therapists in Saskatchewan. ${ }^{50}$

The educational program at the National School of Dental Therapy is fully funded by Health Canada and maintains an affiliation agreement with the School of Dentistry at the University of Saskatchewan. The school accepts twenty students each year into a two-year curriculum. The program is focused on training to care for children, although instruction is also provided in treating dental emergencies in adults, including extraction of permanent teeth.

Each year of the two-year curriculum is forty weeks in length. The basic didactic curriculum in the biomedical sciences and clinical dental sciences is taught in the first year, with the second year devoted primarily to clinical care. Thus the students receive approximately 1,600 clock hours of didactic instruction in the first year and an equivalent amount of clinical instruction the second year, for a total of 3,200 clock hours. (The preceding general information was obtained through personal communication with Dr. Glenn Schnell, director of the National School of Dental Therapy.)

Double-blind studies of the work of the Canadian dental therapists in comparison to federal dentists have been conducted. ${ }^{46,51}$ The results indicated that the restorations placed by dental therapists were equal to those placed by dentists. Trueblood documented the cost-benefit effectiveness of Health Canada's developing and deploying dental therapists in a doctoral dissertation in $1992 .{ }^{52}$

\section{The United States Experience}

In the United States, studies of expanded functions for dental auxiliaries began in the 1960s. During that decade six notable programs studied the delegation of reversible expanded functions to dental assistants: the Great Lakes Naval Training Center, ${ }^{53}$ the Division of Indian Health, ${ }^{54}$ the University of Alabama,${ }^{55}$ the University of Minnesota, ${ }^{56}$ USPHS Dental Manpower Development Center in Louisville, ${ }^{57}$ and a program in Philadelphia.$^{58}$ All demonstrated that reversible procedures could be effectively taught to dental assistants in a reasonable period of time. $^{59}$ 
During the 1970s, the emphasis changed, and studies were conducted involving the delegation of both reversible and irreversible procedures to dental hygienists. Notable among these studies were those at the Forsyth Dental Center ${ }^{60}$ the University of Kentucky, ${ }^{61}$ and the University of Iowa ${ }^{62}$ Before considering these, however, it is important to note that there have been two attempts to develop a New Zealand dental nurse in the United States. Both were met with strong opposition from the practicing profession.

In 1949 the Massachusetts legislature passed a bill authorizing the receipt of funding from the United States Children's Bureau by Forsyth Dental Infirmary for Children to institute a special five-year program of dental research in this area. ${ }^{63,64}$ The research would prepare "feminine personnel," in a two-year training program, to prepare and restore cavities in children's teeth under the supervision of a dentist in a dispensary or clinic approved by the Massachusetts Commissioner of Health. The training program was to be conducted under the supervision of the Department of Health and the Board of Dental Examiners. Thus, the passage of this legislation provided for the establishment of an experimental dental care program for children similar to the school dental nurse of New Zealand.

The reaction of organized dentistry was swift and negative. The ADA House of Delegates passed resolutions "deploring" the program; expressing the view that any such program concerning the development of "sub-level" personnel, whether for experimental purposes or otherwise, be planned and developed only with the knowledge, consent, and cooperation of organized dentistry; and stating that a teaching program designed to equip and train personnel to treat children's teeth cannot be given in a less rigorous course or in a shorter time than that approved for the education of dentists. ${ }^{64}$ Faced with increasing pressure from organized dentistry in Massachusetts, as well as nationally, the Massachusetts governor signed a bill in July 1950 rescinding the enabling legislation. ${ }^{65}$

In February 1972, Dr. John Ingle, dean of the University of Southern California School of Dentistry (USC), proposed the use of school dental nurses, as employed in New Zealand, to address the problem of dental caries among America's school children. ${ }^{66}$ In the spring of that year he authorized the submission, on behalf of USC, of a proposal for a training grant of $\$ 3.9$ million from the U.S. Public Health Service to train dental nurses, with Dr. Jay W. Friedman, who had studied New Zealand's School
Dental Service, as the project director. At the same time, the then-governor of California, Ronald Reagan, established a committee to study the functions of all dental auxiliaries, in order to make recommendations to the California legislature and the State Board of Dental Examiners. ${ }^{67}$ As a result of these two significant developments, the then-two California Dental Associations established a committee to study the New Zealand dental care system, analyze the relationship of the school dental nurse to private practice, assess the work of the school dental nurse, and compare the New Zealand and California systems ${ }^{67}$ The committee of four individuals visited New Zealand in late 1972. Their report, published in 1973 , stated that "there is little doubt that dental treatment needs related to caries for most of the New Zealand children age $2^{1 / 2}$ to 15 have been met." ${ }^{967,68}$ However, the report concluded that the public of California would "probably not" accept the New Zealand type of school dental service, as it would be perceived as a "second class system." Drs. Ingle and Friedman wrote sharp rebukes to the committee's report, pointing out the inconsistencies of the objective findings of the investigation in relation to the subjective conclusions of the report, which they judged to be drawn to placate the practicing profession in California. ${ }^{69,70}$ Dunning also criticized the report's conclusions in a letter to the Journal of the American Dental Association editor, ${ }^{71}$ and Goldhaber, in a Journal of Dental Education article, called the committee's conclusion "absurd." ${ }^{\text {" } 2}$ According to Dr. Ingle, the American Dental Association mounted a nationwide protest against him and the dental nurse project, which probably contributed to the Public Health Service's failure to fund the grant. He subsequently resigned his position as dean at USC to join the staff of the Institute of Medicine. ${ }^{73}$

In 1970 the Forsyth Dental Center initiated what was subsequently designated, and described in a book of the same title, "The Forsyth Experiment." 60 The House of Delegates of the Massachusetts Dental Association had recently passed a resolution favoring research on expanded function dental auxiliaries. Forsyth communicated, to both the Massachusetts Board of Dental Examiners and to the Massachusetts Dental Society, its plans to initiate a research project to train dental hygienists in restorative procedures for children, which were typically reserved for dentists alone. The experiment was designed to teach and evaluate clinical performance for administering local anesthesia and preparing and placing Class I, II, and V amalgam restorations and 
Class III and V composites. No problems were encountered between 1970 and 1973. However, in October 1973 the Board of Dental Examiners notified Forsyth that a hearing would be held to review the project's feasibility. Subsequently, the state board voted unanimously that the drilling of teeth by hygienists was a direct violation of the Dental Practice Act of Massachusetts and submitted such a decision to the attorney general's office for a ruling and action. In March 1974, the attorney general ruled that "drilling teeth is deemed in the act to be undertaking the practice of dentistry, and the legislature had not exempted research from this provision." Forsyth was forced to close its "experiment" in June 1974, but not before it was able to objectively document that hygienists could be taught to provide restorative dental services effectively, efficiently, and at a positive cost-benefit. Whereas the projected curriculum time to achieve the competencies desired was forty-seven thirty-hour weeks, the project was able to achieve its desired educational outcomes in twenty-five thirty-hour weeks.

Another expanded functions project was implemented between 1972 and 1974 at the University of Kentucky, supported by the Robert Wood Johnson Foundation. ${ }^{61}$ This project also involved the training of dental hygienists in restorative dentistry. Thirtysix students, who were completing a four-year baccalaureate program in dental hygiene, participated in a compressed curriculum that provided for 200 hours of didactic instruction in children's dentistry, as well as 150 hours of clinical practice. The program was specifically addressed to providing primary care for the child patient, including administration of local anesthesia, restoration of teeth with amalgams and stainless steel crowns, and pulpal therapy. Toward the conclusion of the curriculum, these hygienists trained in dentistry for children participated in a double-blind study comparing their restorative skills with fourth-year student dentists. No significant differences were found between the quality of their work and that of the student dentists.

At the College of Dentistry at the University of Iowa, a five-year project was conducted between 1971 and 1976, supported by the W.K. Kellogg Foundation, that trained dental hygienists to perform expanded functions in restorative dentistry and periodontal therapy for both children and adults. The results were the same as the studies at Forsyth and Kentucky: hygienists could be effectively trained, in a relatively brief time period, to perform, at a com- parable quality level, procedures that traditionally are reserved solely for dentists. ${ }^{62}$

\section{Justifying a Pediatric Oral Health Therapist}

Despite documentation of the ability of individuals other than dentists to successfully provide quality care to children, both in the United States and internationally, American dentistry has been immovable in its resistance to this type of allied professional. The crisis faced today, as represented by the disparities in oral health among our more disadvantaged populations, demands challenging the traditional practice paradigm and advocating the addition of a new member of the dental team - a pediatric oral health therapist.

Throughout this article, references have been made to circumstances that justify the development of pediatric oral health therapists to help address the disparities in oral health among children in the United States. To summarize:

- There are profound disparities in oral health between the children of the rich and the poor in America.

- There is a general lack of access to care for the nation's disadvantaged children.

- There is a general lack of training of general dentists in children's dentistry in the current predoctoral dental curricula.

- There are insufficient numbers of dentists in urban inner-city and rural areas, where children are most in need of care.

- There are inadequate numbers of minority dentists to work with minority populations.

- There is a declining dentist to population ratio.

- There are far too few pediatric dentists to have an impact on access for disadvantaged populations.

- There is a general lack of interest on the part of dentists in treating children, given the current demand for other dental therapies.

- There is even less interest by dentists in treating low-income children, particularly if their care is being financed by Medicaid or S-CHIP programs.

- There is a need to provide care in a cost-effective manner, particularly for patients whose care is being publicly funded.

- There is ample evidence, from within the United States and internationally, that high school gradu- 
ates can be trained in a two-year academic program to render, under general supervision by a dentist, safe, effective, high-quality preventive and restorative care for children.

All of these circumstances point to the reasonableness and value of developing and deploying pediatric oral health therapists.

\section{Developing Pediatric Oral Health Therapists}

A curriculum for developing pediatric oral health therapists exists and has been documented to be effective in numerous countries throughout the world. It is the traditional curriculum of the school dental nurse/therapist. It is known that high school graduates can safely, effectively, and efficiently provide oral health care for children after two academic years of training. The curriculum for a pediatric oral health therapist could be considered comparable to the two academic year (associate degree) curriculum for preparing dental hygienists: 230 of the 260 dental hygiene training programs in the United States are two-year programs. The primary difference would be the focus of the training - with that of the hygienist being on periodontal disease, particularly in the adult, and the therapist on dental caries, specifically for the child. The curricula would share areas of commonality, such as the basic biomedical sciences, oral biology, preventive dentistry, infection control, the diagnostic sciences, and radiography. The perceptual motor skills required to restore the teeth of children are no more complex than those to perform scaling and root planing. Research has demonstrated these skills can be taught in a two-year program to individuals with a high school degree.

It may be possible to shorten the training period if the students matriculating in a pediatric oral health therapist program were already certified dental hygienists; however, there is reason to encourage hygienists to continue to be the expanded-function allied dental professional for managing adult periodontal health and disease. Hygienists are too valuable in their current role, particularly in the context of their relative shortage and the aging of the population, with concomitant needs for periodontal therapy. Rather, it appears more reasonable to create a new allied dental professional who focuses on the unique oral health needs of children, specifically as these relate to the problem of dental caries.
Where and under what circumstances might a pediatric oral health therapist practice? To effectively address the access problem, it appears practitioners must go to where children are located. As in New Zealand, the most logical place to capture this audience is in the school system. As Dunning stated over thirty years ago, "any large-scale incremental care plan for children, if it is to succeed, must be brought to them in their schools." ${ }^{29}$ A number of our colleges of dentistry are having some success with mobile dental van programs. Such approaches enable student dentists to learn children's dentistry in an era when it is increasingly difficult to draw children in need of dental care to institutional facilities. It is reasonable for pediatric oral therapists to practice (under the general supervision of a dentist) in mobile vans providing care on a financial needs-tested basis, for example, to all Medicaid- and S-CHIPeligible children in a school, moving through the year from one school to another. Such a program, begun in an incremental manner with the youngest children (with the least carious experience and the greatest potential for implementation of preventive care), would seem to be a cost-effective way of managing the oral health needs for our poorest and neediest children.

In New Zealand, a dental therapist with an assistant is responsible for 1,450 children. ${ }^{32}$ The Commonwealth of Kentucky has essentially the same population as New Zealand. Kentucky has 384,832 children ages five to eleven (K-6). Of these, approximately 43 percent (or 172,418 children) live at a level of 200 percent of poverty or below and are eligible for Medicaid/S-CHIP benefits. ${ }^{74}$ Using the New Zealand model, to care for this many children would (hypothetically) require 212 dental therapists. While no direct economic comparisons can be made due to the significantly different circumstances, it is interesting to note that New Zealand spends approximately \$34 million (US) caring for all enrolled children ages six months through seventeen years ${ }^{75}$ and that Kentucky's dental expenditures for children covered by Medicaid/S-CHIP alone in 2002-03 were approximately $\$ 40$ million. $^{76}$

A second potential environment for pediatric oral health therapists could be in the private sector, as exists now in Saskatchewan. In such, therapists could work under the supervision of a dentist and serve as a dentist-extender for children's primary care, in much the same manner that a dental hygienist serves in such a role for adult periodontal care. It does not make economic sense for a dentist to rou- 
tinely perform scaling, root planing, and polishing of teeth, when such can be delegated to a hygienist. Research has documented the economic benefit that dentists gain by employing hygienists. ${ }^{77}$ In like manner, it is not reasonable for dentists to perform primary care procedures for children when a pediatric oral health therapist can do so. Adding such an individual to the dental team not only makes sense; it seems unreasonable, in economic terms, not to proceed as rapidly as possible. However, the profession continues to cling to the belief that cutting tooth structure is paradigmatically different than scaling teeth and such is a boundary never to be crossed by allied professionals. It is a cultural tradition, not a justifiable belief. In Saskatchewan, dental therapists are employed in private offices, frequently caring for all the children in a practice. Saskatchewan dentists testify to the significant economic return on their investment in employing dental therapists, apart from the opportunity it provides to care for more patients and a broader range of patients than one would be able to treat without such personnel. That is improved access. It would be in dentistry's economic selfinterest to develop pediatric oral health therapists able to practice in dental offices.

\section{Values and a Profession}

The ADA Principles of Ethics and Code of Professional Conduct has been revised over the past twenty years to include the classic troika of principles of professional ethics: respect for autonomy, beneficence, and justice. Regarding justice, the Principles state: "In its broadest sense, this principle expresses the concept that the dental profession should actively seek allies throughout society on specific activities that will help improve access to care for all." 78

One of the most important and influential books of political philosophy written in the twentieth century was $A$ Theory of Justice, by the late Professor John Rawls of Harvard University, ${ }^{79}$ in which he carefully explicates the nature of justice. His definition is based on the now famous hypothetical in which he asks one to stand behind a "veil of ignorance" and envision a world into which one will be born, but not knowing into what circumstance he or she will be born, that is, to a rich or poor family, intelligent or dull, male or female. He argues that, given such a condition, people will design a world with some degree of risk aversion, in which the following conditions would exist: 1) each person will have an equal right to the most extensive system of liberties comparable with a system of equal liberties for all; 2) persons with similar skills and abilities will have equal access to offices and positions of society; and 3) (the critical one for our consideration of access and disparities) social and economic institutions will be so arranged as to maximally benefit the worst off. Such a design he affirms would be "just."

Given a Rawlsian view of justice, the oral health care delivery system in the United States, if it is to be just, must be structured to maximally benefit the worst off in society. In reality, as has been demonstrated, it is quite the opposite. Poor and minority children, the most vulnerable individuals in society, are the "worst off" and have the poorest access to oral health care and the poorest oral health. Justice would demand they be maximally benefited, in order that they ultimately have "equal opportunity" to do well. Yet our system is so structured as to maximally benefit those who are already "well off."

The time has come for the profession of dentistry to seriously and courageously provide access to oral health care for all of America's children. Access should be provided in such a manner that major barriers are destroyed, and parents, no matter their economic status, ethnicity, or cultural circumstance, can be assured their children will be treated justly by society, in that they have an equal opportunity, with other children, for good oral health. A method that can be effective in helping achieve this goal is the development of pediatric oral health therapistsallied professionals uniquely trained to care for the oral health of children.

\section{Acknowledgments}

This article was developed during a threemonth sabbatical from the University of Kentucky, spent studying the history of the school dental nurse and dental therapy practice and education in New Zealand and Canada. The author acknowledges with grateful appreciation the hospitality extended to him during this period by: Dr. Thomas Kardos, associate dean for academic affairs, School of Dentistry, University of Otago, Dunedin, New Zealand; Dr. Glenn Schnell, director of the National School of Dental Therapy, First Nations University, Prince Albert, Saskatchewan, Canada; and Dr. Dominick DePaola, president of the Forsyth Institute, Boston, Massachusetts. Suggestions for improving the manuscript by Dr. Jay W. Friedman are also acknowledged with gratitude. 


\section{REFERENCES}

1. Gehshan S, Straw T. Access to oral health services for low-income people: policy barriers and opportunities for intervention for the Robert Wood Johnson Foundation. Forum for State Health Policy Leadership/National Council of State Legislatures, 2002:25.

2. Fulton JT. Experiment in dental care: results of New Zealand's use of school dental nurses. Geneva, Switzerland: World Health Organization, 1951.

3. Brooking TWH. A history of dentistry in New Zealand. Dunedin, New Zealand: New Zealand Dental Association, 1980.

4. Saunders JL. The New Zealand school dental service: its initiation and development, 1920-1960. Wellington, New Zealand: Government Printer, 1964.

5. Oral health in America: a report of the surgeon general. Rockville, MD: U.S. Department of Health and Human Services, National Institute of Dental and Craniofacial Research, National Institutes of Health, 2000:308.

6. National call to action to promote oral health: a publicprivate partnership under the leadership of the office of the surgeon general. Rockville, MD: U.S. Department of Health and Human Services, Public Health Service, National Institutes of Health, National Institute of Dental and Craniofacial Research, 2003:28.

7. Newacheck PW, Hughes DC, Hung YY, Wong S, Stoddard JJ. The unmet health needs of America's children. Pediatrics 2000;104:989-97.

8. Gift HC, Reisine ST, Larach DC. The social impact of dental problems and visits. Am J Public Health 1992;82:1663-8.

9. General Accounting Office. Oral health: dental disease is a chronic problem among low-income populations. Report GAO/HEHS-00-72. Washington, DC: General Accounting Office, 2000. At: www.gao.gov. Accessed: July 24, 2003.

10. Kaste LM, Selwitz RH, Oldakowski JA, Brunelle JA, Winn DM, Brown LJ. Coronal caries in the primary and permanent dentitions of children and adolescents 1-17 years of age: United States, 1988-91. J Dent Res 1996;75:631-41.

11. Federal Register. Federal poverty level, 2003;28:6456-8.

12. U.S. Department of Health and Human Services, Office of the Inspector General. Children's dental services under Medicaid: access and utilization. San Francisco: U.S. Department of Health and Human Services, 1996.

13. Mouradian WE, Berg JH, Somerman MJ. Addressing disparities though dental-medical collaboration, part 1 . The role of cultural competency in health disparities: training of primary care medical practitioners in children's oral health. J Dent Educ 2003;67(8):860-8.

14. Improving the oral health status of all Americans: roles and responsibilities of academic dental institutions. Washington, DC: American Dental Education Association, 2003:22 pages.

15. Oral health: factors contributing to low use of dental services by low-income populations. Washington, DC: General Accounting Office, 2000:41 pages.
16. Dental workforce model, 1997-2020. Chicago: American Dental Association, 1999.

17. Health professions shortage areas. Rockville, MD: Health Resources and Services Administration, U.S. Department of Health and Human Services, 1999.

18. Brown LJ, Lazar V. Minority dentists - why do we need them: closing the gap. Washington, DC: Office of Minority Health, U.S. Department of Health and Human Services, 1999:6-7.

19. Valachovic RW. Dental workforce trends and children. Ambul Pediatrics 2002;2:154-61.

20. Seale NS, Casamassimo PS. U.S. predoctoral education in pediatric dentistry: its impact on access to dental care. J Dent Educ 2003;67(1):23-9.

21. Dental master files. Chicago: American Dental Association, 2002.

22. American Academy of Pediatrics. At: www.aap.org. Accessed: July 24, 2003.

23. Casamassimo P. We need help! pediatric dentistry today. Chicago: American Academy of Pediatric Dentistry, 2000:30 pages.

24. Social Security Act. 42 USC 1396d(r) (2000).

25. Social Security Act. Title XXI. 42 USC 1397 aa (2000).

26. Becker N, Becker DB. Raise your voice. J Mass Dent Soc 2003;52:6.

27. Palmer C. U.S. House resolution lauds Give Kids a Smile campaign. ADA News (American Dental Association), March 17, 2003.

28. Friedman JW. The New Zealand school dental service: lesson in radical conservatism. J Am Dent Assoc 1972;85:609-17.

29. Dunning JM. Deployment and control of dental auxiliaries in New Zealand and Australia. J Am Dent Assoc 1972;85:618-26.

30. New Zealand Ministry of Health toolkit: oral health. At: www.newhealth.govt.nz/toolkits/oralhealth. Accessed: July 24, 2003.

31. Hannah A. New Zealand dentists, dental therapists, and dental hygienists. Work Force Analysis, 1998. Wellington, New Zealand: Dental Council of New Zealand, 1998.

32. Roddick A, principal dental officer, Otago, Dunedin, New Zealand. Personal communication, May 2003.

33. Kardos T, associate dean for academic affairs, School of Dentistry, University of Otago, Dunedin, New Zealand. Personal communication, May 2003.

34. Stanley B. How do we enhance the consumer-provider partnership? N Z Dent J 2000;96:106-8.

35. Thomson WM, associate professor, dental public health, School of Dentistry, University of Otago, Dunedin, New Zealand. Personal communication, May 2003.

36. Drummond DB, associate professor of pediatric dentistry, School of Dentistry, University of Otago, Dunedin, New Zealand. Personal communication, May 2003.

37. King A. Oral health forum 2000: opening address by the minister of health, the Honourable Annette King. N Z Dent J 2000;96:84-6.

38. Improving child oral health and reducing child oral health inequalities: report to the minister from the Public Health Advisory Committee. Wellington, New Zealand: National Health Committee, 2003:94 pages. 
39. Walsh J. International patterns of oral health care: the example of New Zealand. Harvard Dental Alumni Bulletin, 1968.

40. Walsh J. International patterns of oral health care: the example of New Zealand. N Z Dent J 1970;66:143-52.

41. Vargas CM, Crall JJ, Schneider DA. Sociodemographic distribution of pediatric dental caries: NHANES III, 19881944. J Am Dent Assoc 1998;129:1229-38.

42. University of Otago School of Dentistry. Job outlook. At: healthsci.otago.ac.nz/Division/dental/ther-fact.html. Accessed: July 24, 2003.

43. Roder DM. The employment of dental nurses. J Public Health Dent 1978;38:159-71.

44. World Health Organization. World oral health country/ area profile programme. Malmo, Sweden: World Health Organization Collaborating Center, 2003. At: www.whocollab.od.mah.se. Accessed: July 24, 2003.

45. Davey K. Dental therapists in the Canadian north. J Can Dent Assoc 1974;40:287-91.

46. Schnell GM. The federal dental therapy program: a dream and the reality. Unpublished manuscript, 22 pages.

47. Keenan GW. The Saskatchewan dental nurse. J Can Dent Assoc 1975;41:344-5.

48. Health Canada. At: www.hc-sc,gc.ca/english/. Accessed: July 24, 2003.

49. Province of Saskatchewan. Dental Disciplines Act. The Statutes of Saskatchewan, 2001. At: www.hrha.sk.ca/Images1/D4-1.pdf. Accessed: July 17, 2003.

50. Reed C, registrar, Saskatchewan Dental Therapists Association. Personal communication. July 23, 2003.

51. Ambrose ER, Hord AB, Simpson WJA. Quality evaluation of specific dental services provided by the Saskatchewan dental plan: final report. Regina, Saskatchewan, 1976:19 pages.

52. Trueblood RG. An analytical model for assessing the costs and benefits of training and utilizing auxiliary health personnel with application to the Canadian Dental Therapy Program. Montreal: Department of Educational Technology, Concordia University, 1992:276 pages.

53. Ludwick WE, Schnoebelen EO, Knoedler DJ. Greater utilization of dental technicians: report of training, 1963. Great Lakes, IL: U.S. Naval Training Center, 1964.

54. Abramowitz J. Expanded functions for dental assistants: a preliminary study. J Am Dent Assoc 1966;72:386-91.

55. Hammon PE, Jamison HC. Expanded functions for dental auxiliaries. J Am Dent Assoc 1967;75:658-72.

56. Rosenblum FN. Experimental pedodontic auxiliary training program. J Am Dent Assoc 1971;82:1082-9.

57. Lotzkar S, Johnson, DW, Thompson MB. Experimental program for expanded functions for dental assistants: phase one, baseline and phase two, training. J Am Dent Assoc 1971;82(5):1067-81.

58. Soricelli DA. Implementation of the delivery of dental services by auxiliaries: the Philadelphia experiment. Am J Public Health 1973;62:1077-87.

59. Sisty NL, Henderson WG, Paule CL. Review of training and evaluation studies in expanded functions for dental auxiliaries. J Am Dent Assoc 1979;98:233-48.
60. Lobene R. The Forsyth experiment: an alternative system for dental care. Cambridge: Harvard University Press, 1979.

61. Spohn EE, Chiswell LR, Davison DD. The University of Kentucky experimental duties dental hygiene project. University of Kentucky, 1976. Unpublished report.

62. Sisty NL, Henderson WG, Paule CL, Martin JF. Evaluation of student performance in the four-year study of expanded functions for dental hygienists at the University of Iowa. J Am Dent Assoc 1978;97:613-27.

63. American Dental Association. House of delegates action on dental nurses program questioned by Massachusetts commissioner of health. J Am Dent Assoc 1959;40: 363-6.

64. New York Dental Association. The Massachusetts dental research project. N Y J Dent 1950;20:378-83.

65. American Dental Association. Massachusetts dental nurse bill rescinded. J Am Dent Assoc 1950;41:371.

66. Ingle JI. American dental care, 1972: a plan designed to deliver preventive and therapeutic dental care to the children of America. Paper presented at the Conference of Dental Examiners and Dental Educators, Chicago, 1972:23 pages.

67. Redig D, Dewhirst F, Nevit G, Snyder M. Delivery of dental services in New Zealand and California. J So Calif Dent Assoc 1973;41:318-51.

68. American Dental Association. Delivery of dental services in New Zealand and California: summary of a report to the California Dental Association and the Southern California Dental Association. J Am Dent Assoc 1973;87: 542-3.

69. Friedman JW, Ingle JI. New Zealand dental nurses. J Am Dent Assoc 1973;8:1331.

70. Friedman JW, Ingle JI. New Zealand dental nurse report. J Calif Dent Assoc 1973;1:7-8.

71. Dunning JM. New Zealand summary. J Am Dent Assoc 1974;88:271-2.

72. Goldhaber P. Improving the dental health status in the United States: putting your money where your mouth is. J Dent Educ 1977;41:50-8.

73. Ingle JI. Personal communication, October 2003.

74. Kids count. State demographic data, 2003. At: www.aecf.org/kidscount/database/. Accessed: July 24, 2003.

75. Wright C. Keynote address: principles of oral health services planning. N Z Dent J 2000;96:87-93.

76. Cecil J, state dental director, Commonwealth of Kentucky. Personal communication, July 2003.

77. Pride JR. Dental hygiene: adding value to your practice. J Am Dent Assoc 1993;214:251-3.

78. Principles of ethics and code of professional conduct. Chicago: American Dental Association, 2003.

79. Rawls J. A theory of justice. Cambridge: Harvard University Press, 1972. 